\title{
Inclusion of tetramethylpyrazine in channels of the organic zeolite 2,4,6-tris(4-bromophenoxy)-1,3,5-triazine
}

\author{
Gaëtan Couderc · Michel Bonin · Gaël Labat • \\ Ricarda Berger $\cdot$ Jürg Hulliger
}

Received: 10 January 2008/ Accepted: 26 February 2008/Published online: 15 March 2008

(C) Springer Science+Business Media B.V. 2008

\begin{abstract}
2,4,6-tris(4-bromophenoxy)-1,3,5-triazine (BrPOT) features a channel size (11-12 $\AA$ ) allowing the inclusion of large guest molecules such as tetramethylpyrazine (TMPZ). TMPZ forms $\pi$-stacks (d: $3.5 \AA$ ) along channels of BrPOT and shows rotational disorder for methyl positions. Co-inclusions of $\mathrm{I}_{2}$ resulted in a doped state where $I_{2}$ molecules are oriented perpendicular to the channel axis with positional disorder as well. The particular orientation of $I_{2}$ molecules is evident from the observed dichroism.
\end{abstract}

Keywords Host-guest systems · Inclusion compounds · Organic zeolites

The triazine family [1] of channel inclusion compounds is of particular interest, because a channel size of about 10 $12 \AA$ opens up opportunities for hosting guest molecules of a much larger diameter than possible for the 4-5 $\AA$ class of many other host compounds [2]. Given the large diameter, an intuitive view might assume that elongated prolate type molecules based on trans disubstituted benzene rings (biphenyls, stilbenes, etc...) would enter the channel by a packing mode with overlapping guest species. However, this seems not to be the case, because it was found that this functional class of molecules might only be included in the

Electronic supplementary material The online version of this article (doi:10.1007/s10847-008-9433-5) contains supplementary material, which is available to authorized users.

G. Couderc · M. Bonin · G. Labat · R. Berger · J. Hulliger $(\bowtie)$

Department of Chemistry and Biochemistry, University of

Berne, Freiestrasse 3, Berne 3012, Switzerland

e-mail: publication.hulliger@iac.unibe.ch presence of fitting solvent molecules. This applies as well to $\mathrm{C}_{60}$ and $\mathrm{C}_{70}$ [3] for which no solvent free inclusions in e.g. 2,4,6-tris(4-bromo-phenoxy)-1,3,5-triazine (BrPOT) and 2,4,6-tris(4-bromo-3,5-difluorophenoxy)-1,3,5-triazine (Br-3,5-DFPOT) could be prepared so far. The more interesting is the fact that cylindrical types of molecules, such as decamethyl-bis-cyclopentadienyl-metallate $\left(\mathrm{M}\left(\mathrm{cp}^{*}\right)_{2}\right)$ molecules enter the channels without necessity of a solvent co-inclusion. And most surprisingly the combination of $\mathrm{M}\left(\mathrm{cp}^{*}\right)_{2}$ and $\mathrm{C}_{60}, \mathrm{C}_{70}$ does it as well, whereas $\mathrm{C}_{60}\left(\mathrm{CH}_{3}\right)_{5}$ - Fecp [3] requires again solvent co-inclusion. So, these triazine channels obviously provide sites, where optimally (length) cylindrical molecules may allow 1D close packing being interesting for physical property generation (charge transport, magnetism).

Here, we present the inclusion of tetramethylpyrazine (TMPZ), which represents a further guest, although not of a proper symmetry in respect to a trigonal or hexagonal channel, which enters by a stacking of aromatic rings. Attempts were made to intersect this $1 \mathrm{D}$ stack with $\mathrm{I}_{2}$, showing, however, that only a low level $\mathrm{I}_{2}$ may substitute TMPZ entering the channel with the molecular axis at $\mathrm{I}_{2}$ perpendicular to $\mathrm{c}$.

Preparation of crystals: Needle-shaped crystals (size: $1.2 \times 0.2 \times 0.2 \mathrm{~mm}^{3}$ ) were obtained by slow cooling $\left(1{ }^{\circ} \mathrm{C} / \mathrm{h}\right)$ of a toluene solution containing a mixture of BrPOT and TMPZ. The nature of solvent and the quantity of TMPZ engaged in preparation were of crucial importance: Butanone, mesitylene, and carbon disulfide did not yield crystals being stable against a loss of guests after getting out of the nutrient. Presumably, in the case of toluene we were obtaining a solvent free inclusion for TMPZ. Attempts to obtain a mixed chain of TMPZ and $\mathrm{I}_{2}$ or at least a doped TMPZ chain were using particular relative amounts in the nutrient (see Table 1). 
Samples A, B, D, and E were stable at long term and thus used for the analysis (DSC: decomposition above $\sim 120{ }^{\circ} \mathrm{C}$ ). $\mathrm{C}$ and $\mathrm{F}$ probably were co-inclusions with toluene accepting more iodine than others. Solution ${ }^{1} \mathrm{H}-\mathrm{NMR}$ showed for A, B, D, and E a molar ratio of 1.0(1):1.0(1) for BrPOT/TMPZ and no presence of toluene. Thermogravimetry confirmed these results (Fig. 1). The mass loss corresponded to a ratio of 1.0(1):1.0(1) and no significant amount of $\mathrm{I}_{2}$ was detected.

The small concentration of $\mathrm{I}_{2}$ inside channels was measured by ICP-MS: A few mg of crystals (B, D, E) were destroyed in $\mathrm{HNO}_{3}(68 \%)$ and finally diluted in water to $1: 10$ for being measured by an ICP-MS Varian 820 MS. The found concentrations for $\mathrm{I}_{2}$ of $320 \mathrm{ppm}$ (B), $80 \mathrm{ppm}$ (D), and $50 \mathrm{ppm}$ (E) scale well with the decreasing color intensity of crystals. A blank test for A showed no $\mathrm{I}_{2}$. To demonstrate that $\mathrm{I}_{2}$ is really present within channels, the pronounced dichroism was used for confirmation. In Fig. 2, the maximum absorption is obtained for a polarization perpendicular to the channels. The optical absorption for a polarization along $\mathrm{c}$ was not significant. Because of $\mathrm{I}_{2}$ perpendicular to $\mathrm{c}$, a rotation of the needle around $\mathrm{c}$ might show an extinction of color or not. In the first case, this would indicate ordering in the $(a, b)$ plan. However, the overall hexagonal symmetry of the inclusion (Table 2) would not support this. From observation of a crystal rotated around the c-axis, we can conclude

Table 1 Conditions and results of crystallization $(1 \mathrm{ml}$ solution of toluene, cooling rate of $1{ }^{\circ} \mathrm{C} / \mathrm{h}$ starting from $70{ }^{\circ} \mathrm{C}$ to room temperature)

\begin{tabular}{llll}
\hline $\begin{array}{l}\text { Sample } \\
\text { no. }\end{array}$ & $\begin{array}{l}\text { BrPOT/TMPZ / } \\
\text { Iodine (molar ratio) }\end{array}$ & Color & Remarks \\
\hline A & $1 / 13.3 / 0$ & Colorless & Stable in air \\
B & $1 / 70.40 / 4.53$ & Yellow & Stable in air \\
C & $1 / 3.25 / 0.96$ & Yellow & Not stable in air \\
D & $1 / 34.11 / 1.59$ & Light yellow & Stable in air \\
E & $1 / 4.19 / 1.14$ & Slight yellow & Stable in air \\
F & $1 / 1.12 / 0.92$ & Orange & Not stable in air \\
\hline
\end{tabular}

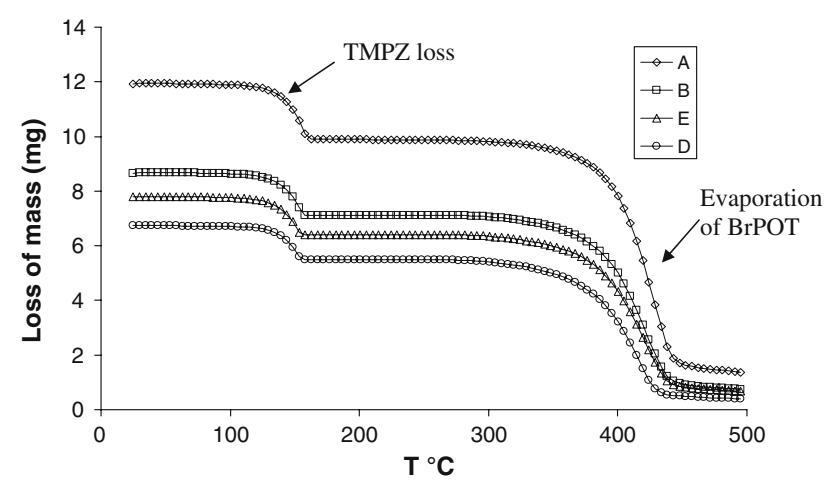

Fig. 1 Thermogravimetry for samples A, B, E, and D showing a loss of TMPZ

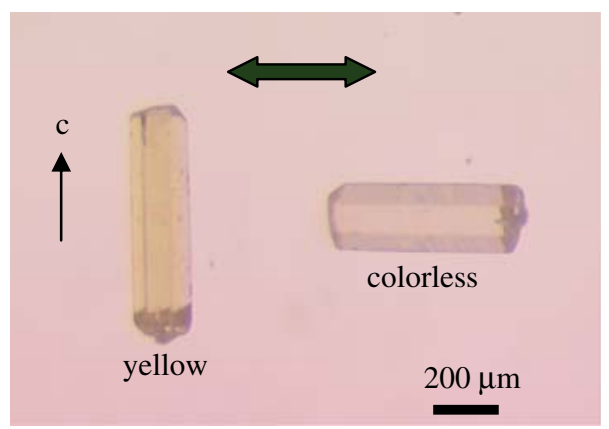

Fig. 2 Dichroism of a crystal of type $B \operatorname{BrPOT}(T M P Z)\left(I_{2}\right)_{x}(x$ : $320 \mathrm{ppm}$ ). The arrow shows the direction of polarization. (Color picture available on the web)

Table 2 Crystal data

\begin{tabular}{|c|c|c|}
\hline & A & B \\
\hline $\begin{array}{l}\text { Crystallization } \\
\text { method }\end{array}$ & Slow cooling & Slow cooling \\
\hline \multirow[t]{2}{*}{ Empirical formula } & $\mathrm{C}_{21} \mathrm{H}_{12} \mathrm{Br}_{3} \mathrm{~N}_{3} \mathrm{O}_{3}$ & $\mathrm{C}_{21} \mathrm{H}_{12} \mathrm{Br}_{3} \mathrm{~N}_{3} \mathrm{O}_{3}$ \\
\hline & $\mathrm{C}_{8} \mathrm{H}_{12} \mathrm{~N}_{2}$ & $\mathrm{C}_{8} \mathrm{H}_{12} \mathrm{~N}_{2}$ \\
\hline $\begin{array}{l}\text { Formula wt. } \\
\left(\mathrm{g} \mathrm{mol}^{-1}\right)\end{array}$ & 730.26 & 730.26 \\
\hline Crystal color & Colorless & Yellow \\
\hline Crystal shape & Prism & Prism \\
\hline $\mathrm{T}(\mathrm{K})$ & 293(2) & 293(2) \\
\hline$\lambda(\AA)$ & 0.71073 & 0.71073 \\
\hline Crystal size $\left(\mathrm{mm}^{3}\right)$ & $0.20 \times 0.18 \times 0.16$ & $0.51 \times 0.17 \times 0.13$ \\
\hline Crystal system & Hexagonal & Hexagonal \\
\hline Space group & $\mathrm{P}_{3} / \mathrm{m}$ & $\mathrm{P}_{3} / \mathrm{m}$ \\
\hline a $(\AA)$ & $15.695(2)$ & $15.669(2)$ \\
\hline b $(\AA)$ & $15.695(2)$ & $15.669(2)$ \\
\hline c $(\AA)$ & $7.1085(14)$ & $7.1052(14)$ \\
\hline$\alpha\left({ }^{\circ}\right)$ & 90 & 90 \\
\hline$\beta\left({ }^{\circ}\right)$ & 90 & 90 \\
\hline$\gamma\left({ }^{\circ}\right)$ & 120 & 120 \\
\hline $\mathrm{V}\left(\AA^{3}\right)$ & $1516.4(4)$ & $1510.7(4)$ \\
\hline Z & 2 & 2 \\
\hline$\rho\left(\mathrm{g} \mathrm{cm}^{-3}\right)$ & 1.599 & 1.605 \\
\hline $2 \theta \max \left({ }^{\circ}\right)$ & 63.89 & 58.71 \\
\hline$\mu\left(\mathrm{Mo}_{\mathrm{K} \alpha} / \mathrm{mm}^{-1}\right)$ & 4.03 & 4.04 \\
\hline Measured reflect & 18474 & 14630 \\
\hline Independent reflect & $1876 / \mathrm{I}>2 \sigma(\mathrm{I}) 1383$ & $1479 / \mathrm{I}>2 \sigma(\mathrm{I}) 1250$ \\
\hline $\mathrm{R}_{\text {int }}$ & 0.0519 & 0.0394 \\
\hline $\mathrm{R}_{1}$ & $\begin{array}{l}\mathrm{I}>2 \sigma(\mathrm{I}) 0.0523 / \\
\quad 0.0780\end{array}$ & $\begin{array}{l}\mathrm{I}>2 \sigma(\mathrm{I}) 0.0444 / \\
\quad 0.0542\end{array}$ \\
\hline$w_{2}$ & 0.1398 & 0.1243 \\
\hline $\operatorname{CCDC} \mathrm{n}^{\circ}$ & 667809 & 667810 \\
\hline
\end{tabular}

Note: Cambridge Crystallographic Data Centre (CCDC) contains the supplementary data for this paper. These data can be obtained free of charge from the CCDC via www.ccdc.cam.ac.uk/data_request/cif 


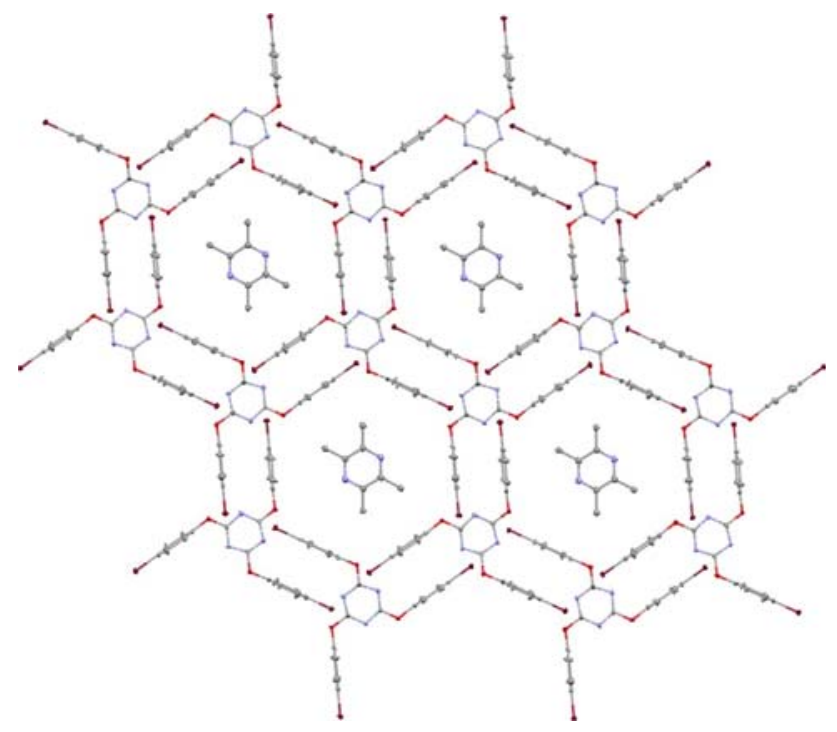

Fig. 3 Typical hexagonal packing layer of BrPOT(TMPZ). For clarity only one possible orientation of three of the pyrazine guest molecules is shown

that no preferred $I_{2}$ orientation in the $(a, b)$ plane is evident for sample B.

For a structural analysis, crystals of sample A, B, and D were mounted on a Stoe Mark II-imaging plate diffractometer system [4] equipped with a graphite monochromator. Data collection, using $\mathrm{Mo}-\mathrm{K}_{\alpha}$ radiation $\left(\lambda=0.71073 \AA\right.$ ), was performed at $-100{ }^{\circ} \mathrm{C}$ for sample $\mathrm{B}$ and room temperature for sample A. Exposures were obtained at an image plate distance of $80 \mathrm{~mm}$ with $\varphi=0^{\circ}$ and $0<\omega<180^{\circ}$ for the crystal oscillating through $1^{\circ}$ in $\omega$. The structure was solved by direct methods using the program SHELXS-92 [5] and refined by full matrix least squares on $\mathrm{F}^{2}$ with SHELXL-97 [6]. The hydrogen atoms were included in calculated positions and treated as riding atoms. The diameter of the channel was estimated by using the Mercury visualization software [7]. The crystallographic data are reported in Table 2.

Both types of crystals, A, B (see Table 2) crystallize in the hexagonal space group $\mathrm{P}_{3} / \mathrm{m}$, typical for many triazine inclusion compounds. As the two-fold molecular symmetry of the TMPZ is incompatible with the 3 -fold channel symmetry (Fig. 3), rotational disorder is present. Three TMPZ's share one site, each of them rotated by $120^{\circ}$. The main feature of the structural analysis reveals a stacking of pyrazine moieties (stacking: $3.5 \AA$ ) along the channels. There, the pyrazine is located at the center of the cavity formed by 3 bromo-phenoxy groups of host molecules. Obviously, this system is not adapting a mixed stack of
TMPZ and $I_{2}$ as found in pyrazine $\cdots I_{2}$ on pure crystals [8] and in the channels of tris(o-phenylenedioxy)cyclotriphosphazene (TPP), where pyrazine and $\mathrm{I}_{2}$ form an alternate pyrazine $\cdots \mathrm{I}_{2} \cdots$ pyrazine $\cdots \mathrm{I}_{2}$ packing $[9]$.

Acknowledgments This work was supported by the Swiss National Foundation, project Nr. 200021-113358/1. We thank Prof. U. Krähenbühl for ICP-MS measurements.

\section{References}

1. Saha, B.K., Jetti, R.K.R., Reddy, L.S., Aitipamula, S.: Halogen trimer-mediated hexagonal host framework of 2,4,6-tris(4-halophenoxy)-1,3,5-triazine: Supramolecular isomerism from hexagonal channel $(\mathrm{X}=\mathrm{Cl}, \mathrm{Br})$ to cage structure $(\mathrm{X}=\mathrm{I})$, Cryst. Growth Design. 5, 887-899 (2005); Saha, B.K., Aitipamula, S., Banerjee, R., Nangia, A., Jetti, R.K.R., Boese, R., Lam, C.-K., Mak, T.C.W.: Hexagonal host framework of syn-aryloxytriazines stabilized by weak intermolecular interactions. Mol. Cryst. Liq. Cryst. 440, 295-316 (2005); Jetti, R.K.R., Xue, F., Mak, T.C.W., Nangia, A.: 2,4,6-tris-4-(bromophenoxy)-1,3,5-triazine: a hexagonal host framework assembled with robust $\mathrm{Br}$... $\mathrm{Br}$ trimer synthons. Cryst. Eng. 2, 215-224 (1999); Reichenbächer, K., Süss, H.I., Stoeckli-Evans, H., Bracco, S., Sozzani, P., Weber, E., Hulliger, J.: Modification of channel structures by fluorination, New J. Chem. 28, 393-397 (2004)

2. Allrock, H.R., Siegel, L.A.: Phosphonitrilic compounds. III. 1 Molecular inclusion compounds of tris(o-phenylenedioxy)phosphonitrile trimer. J. Am. Chem. Soc. 86, 5140-5144 (1964); Hertzsch, T., Kluge, S., Weber, E., Budde, F., Hulliger, J.: Surface recognition of dipolar molecules entering channels of the organic zeolite tris $(o$-phenylenedioxy)cyclotriphosphazene, Adv. Mater. 13, 1864-1867 (2001)

3. Suess, H.I., Lutz, M., Hulliger, J.: Inclusion of fullerenes into channels of 2,4,6-tris-4-(bromophenoxy)-1,3,5-triazine (BrPOT), Cryst. Eng. Comm. 4, 610-612 (2002); Reichenbächer, K., Neels, A., Stoeckli-Evans, H., Balasubramaniyan, P., Müller, K., Matsuo, Y., Nakamura, E., Weber, E., Hulliger J.: New fluorinated channeltype host compounds, Cryst. Growth Design. 7, 1399-1405 (2007); Bonin, M., Lüthi, T.A., Reichenbächer, K., Bürgi, H.-B., Hulliger, J.: Inclusion of $\mathrm{C}_{60}$ into cages of 2,4,6-tris(4-iodophenoxy)-1,3,5triazine and classification of known triazine related inclusion structures, to be submitted

4. Stoe \& Cie.: IPDS Software, Stoe \& Cie GmbH, Darmstadt, Germany, (2005)

5. Sheldrick, G.: Phase annealing in SHELX-90: direct methods for larger structures. Acta. Cryst. A46, 467-473 (1990)

6. Sheldrick, G.: SHELXL-97, Program for crystal structure refinement, University of Göttingen, Germany (1997)

7. Mac Rae, C.F., Edgington, P.R., McCabe, P., Pidcock, E., Shields, G.P., Taylor, R., Towler, M., van de Streek, J.: Visualization and analysis of crystal structures. J. Appl. Cryst. 39, 453-457 (2006)

8. Bailey, R.D., Buchanan, M.L., Pennington, W.T.: Molecular complexes of 1,4-diazines with iodine. Acta Cryst. C48, 22592262 (1992)

9. Couderc, G., Bonin, M., Neels, A., Hauser, J., Sozzani, P., Hulliger, J.: Iodine-pyrazine chain inside the channel of tris $(o-$ phenylenedioxy)cyclotriphosphazene, to be submitted 